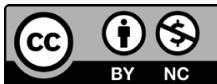

\title{
PROBLEMAS DA TEORIA DAS FONTES DO DIREITO À LUZ DA IDEIA DE DIREITO COMO INTEGRIDADE DE RONALD DWORKIN
}

\author{
PROBLEMS OF SOURCES OF LAW THEORY FROM THE \\ IDEA OF RONALD DWORKIN'S LAW AS INTEGRITY
}

José Emílio Medauar Ommati

Alexandre de Castro Coura

\section{RESUMO}

0 presente texto pretende evidenciar os problemas da tradicional teoria das fontes do Direito em face da noção de que Direito é um empreendimento coletivo e uma prática social interpretativa, como apresenta Ronald Dworkin em sua teoria do Direito como Integridade. Assim, pretendemos mostrar que a teoria das fontes do Direito parte do pressuposto positivista no sentido de que o Direito seria uma mera questão de fato, a partir da existência de uma regra de reconhecimento, padecendo, nesse ponto, daquilo que Dworkin denomina de aguilhão semântico. Retirando-se o aguilhão semântico, passa-se a perceber o Direito como um conceito interpretativo, incompatível com uma teoria das fontes que pretenda relevar, de antemão e de forma unívoca, o que seja o direito válido.

Palavras-chave: Teoria do direito. Fontes do direito. Direito como integridade. Positivismo jurídico. Regra de reconhecimento. 


\section{ABSTRACT}

This paper highlights the problems of the theory of the sources of law considering that law is a collective enterprise and an interpretative social practice, as presented by Ronald Dworkin. Thus, the paper shows that the theory of the sources of law starts from the positivist assumption that law would be a mere matter of fact, from the existence of a rule of recognition, suffering, at this point, from what Dworkin calls semantic sting. Removing the semantic sting, it is possibly understanding law as an interpretative concept, incompatible with a sources of law theory that intends to discovery, beforehand and in a univocal way, what is the valid law.

Keywords: Jurisprudence. Sources of law. Law as integrity. Legal positivism. Rule of recognition.

\section{INTRODUÇÃo}

0 presente texto pretende mostrar a necessidade de se abandonar a teoria das fontes do Direito se assumirmos o Direito como um empreendimento coletivo e uma prática social interpretativa, como apresenta Ronald Dworkin em sua teoria do Direito como Integridade.

Assim, pretendemos mostrar que a teoria das fontes do Direito parte do pressuposto positivista no sentido de que o Direito seria uma mera questão de fato, algo que pode ser descoberto de antemão e objetivamente pelo intérprete, a partir da existência de uma regra de reconhecimento. Todavia, ao se evidenciar os equívocos decorrentes dessa perspectiva, decorrentes do que Dworkin denominou "aguilhão semântico", passa-se a perceber o Direito como um conceito interpretativo incompatível com as pretensões positivistas da tradicional teoria das fontes do Direito.

Para tanto, em um primeiro momento, iremos reconstruir a teoria das fontes do Direito tal como ainda hoje é ensinada por nossos Manuais de Introdução ao Direito. Aqui, em razão de seu caráter didático e pela importância do autor, apresentaremos como a teoria das fontes do Direito se coloca na perspectiva de Dimitri Dimoulis. ${ }^{1}$

Em um segundo momento, reconstruiremos a teoria positivista do Direito de Herbert L.A. Hart, um dos principais autores do positivismo 
jurídico da segunda metade do século XX, pois estaremos interessados em sua compreensão do Direito como uma questão de fato, a partir da defesa que o autor faz da existência de uma regra de reconhecimento. ${ }^{2}$ Mostraremos que, apesar de Hart não explicitar e fundamentar uma teoria das fontes do Direito, a defesa que o autor faz da regra de reconhecimento levaria necessariamente a que se estabelecesse uma teoria das fontes do Direito.

Por fim, mostraremos as principais críticas de Dworkin ao positivismo jurídico de Hart e como tais críticas quanto à regra de reconhecimento evidenciam os problemas da tradicional teoria das fontes do Direito, num contexto em que a pretensão de se definir, previamente, o que seja o Direito válido numa sociedade mostra-se inconsistente.

\section{REVISITANDO A TEORIA DAS FONTES DO DIREITO}

A tradicional concepção positivista acerca da teoria das fontes do Direito preocupa-se em identificar as normas que provêm de certas fontes, como critério de identificação dos comandos juridicamente vinculantes numa sociedade. Qualquer estudante, logo em seu primeiro período em uma Faculdade de Direito, entrará em contato com essa perspectiva teórica.

De acordo com essa perspectiva tradicional, as fontes do Direito seriam os locais onde o Direito nasce. ${ }^{3}$ A metáfora da fonte está claramente associada ao lugar do surgimento da água, a nascente. Assim como um rio teria sua fonte, sua nascente, o Direito também nasceria a partir de locais específicos.

Tal metáfora evidencia também a pretensão de se atribuir ao Direito características essenciais que permitam identificá-lo, como acontece com a água na natureza. Essa perspectiva parece presumir que a vinculação de uma norma a uma determinada fonte resolveria a questão de se saber se esta norma é ou não juridicamente vinculante a um caso concreto. Todavia, como se verá, o direito é um conceito interpretativo dinâmico, que varia no tempo e à luz das peculiaridades do caso concreto. ${ }^{4}$

De acordo com essa teoria tradicional, tão bem representada pelo Professor Dimitri Dimoulis, as fontes do Direito podem se dividir em fontes 
formais e fontes materiais. Para o autor em comento e isso se repete em praticamente todos os autores de Introdução ao Estudo do Direito, as fontes materiais ou genéticas são os fatores que criam o direito, dando origem aos dispositivos válidos. ${ }^{5}$

De acordo com Dimoulis, a questão das fontes materiais do Direito seria bastante controvertida e arremata da seguinte forma:

Consideramos que a verdadeira fonte do direito é indicada pelas teorias do conflito social. 0 direito não se cria com base em valores, ideais ou necessidades da sociedade em geral. 0 direito é um fenômeno histórico, que exprime a vontade política dominante em determinado momento. Não cabe aqui o aprofundamento da questão. 0 estudo das fontes materiais é objeto da sociologia do direito e, em parte, da teoria do Estado e da ciência política. 0 operador jurídico que deseje identificar e interpretar o direito em vigor não deve se preocupar, na sua prática cotidiana, com a pesquisa das fontes materiais. ${ }^{6}$

Aqui, já nos parece claro que o autor compartilha do pressuposto positivista hartiano no sentido de que o Direito é uma mera questão de fato, pois o Direito não se cria com base em valores, ideais ou necessidades da sociedade em geral, se configurando tão-somente como um fenômeno histórico, exprimindo a vontade política dominante em determinado momento.

No entanto, quando o autor se volta para a análise das fontes formais do Direito que sua vinculação ao positivismo jurídico se torna mais patente.

De acordo com Dimoulis, cada ordenamento jurídico possui suas fontes formais. E como esse termo deve ser compreendido? Mais uma vez, com a palavra o autor:

O termo indica os "lugares" nos quais se encontram os dispositivos jurídicos e onde as pessoas devem pesquisar sempre que desejem tomar conhecimento do direito em vigor. Essas fontes são denominadas formais porque dão forma ao direito, porque "formulam" os dispositivos válidos. ${ }^{7}$

Todavia, nem as concepções formais nem materiais de fontes do Direito podem demonstrar o que o Direito realmente é. A concepção formal é insuficiente porque nem todas as razões utilizadas pelos órgãos legitimados pela constituição derivam explicitamente de um ato normativo 
prévio. A concepção material padece de consistência, pois não há uma causalidade direta entre os fatores extrajurídicos que geram o Direito e o conteúdo das decisões de concretização e aplicação normativas. ${ }^{8}$

A rigor, à luz da tradicional teoria das fontes, o Direito acaba resumido a um catálogo fixo de regras, preso a um positivismo jurídico que não consegue explicar em que sentido o fenômeno jurídico é construído por uma prática social ${ }^{9}$, algo mais complexo do que o suposto reflexo estático da lei ou de qualquer outra "fonte" preestabelecida.

É exatamente isso que mostraremos no próximo tópico.

\section{A RELAÇÃO DA TEORIA DAS FONTES DO DIREITO COM $O$ POSITIVISMO JURÍDICO DE HERBERT HART}

Como mostramos acima, a teoria das fontes do Direito possui uma íntima conexão com o positivismo jurídico, na medida em que pensa e compreende o Direito como uma mera questão de fato. Nessa linha, o positivismo jurídico não reconhece que o sentido do Direito só é concretizado no momento da aplicação normativa, em face do caso concreto, algo que não pode ser revelado "a priori" por qualquer fonte.

Essa questão ficará mais clara a partir de agora quando reconstruirmos a teoria do Direito de Herbert L.A. Hart.

Já no início da obra de Hart, encontramos sua vinculação positivista, na medida em que separa de maneira radical descrição de prescrição. Nesse sentido:

De fato, um dos temas centrais do livro é que nem o direito nem nenhuma outra forma de estrutura social podem ser compreendidos sem que se tenham em conta certas distinções cruciais entre dois tipos diferentes de enunciados, a que chamei "internos" e "externos", que podem ambos ser elaborados sempre que normas sociais sejam observadas. ${ }^{10}$

Em outras palavras, Hart pretenderá apresentar um conceito de direito a partir da observação de como o direito funciona. Daí sua vinculação ao positivismo jurídico, pois essa corrente teórica, embora 
profundamente diversificada, compartilha da tese da possibilidade de apenas descrever o objeto sem influir no próprio objeto. ${ }^{11}$

Hart pretende construir um modelo alternativo de Direito no mundo anglo-saxão que pudesse explicar melhor o fenômeno jurídico, já que vigorava tanto na Inglaterra como nos Estados Unidos, que o Direito seria fruto da ordem de um soberano e seria sempre dotado de sanção. Essa era a perspectiva de John Austin, jurista de meados do século XIX, que construiu uma teoria que foi aceita durante vários anos.

Revendo essa perspectiva, Hart afirmará, ao contrário de Austin, que o que explica o Direito não é apenas um conjunto coercitivo de regras. Isso porque o Direito é muito mais rico do que isso: é formado também por regras que conferem poderes ou competências, como também pela regra de reconhecimento. ${ }^{12}$

Na feliz compreensão de Bruno Torrano sobre a teoria de Hart, é correto dizer que Hart elabora três críticas básicas à teoria de Austin:

1. na doutrina atacada, o hábito geral de obediência do súdito não encontra correspondência no soberano, que, eximido deste hábito, fica fora do alcance de qualquer lei; mas mesmo as leis penais, padrões mais próximos à noção austiniana de ordem coercitiva, impõem deveres tanto aos indivíduos quanto às próprias autoridades que as elaboram.

2. qualquer sistema jurídico possui leis positivadas cuja função não é exigir ou permitir que pessoas façam ou deixem de fazer algo, mas sim conferir-lhes poder para a livre criação de direitos e deveres jurídicos; mais do que isso, nem toda a normatividade do direito advém da promulgação de leis, ou, mais estritamente, de ordens dirigidas de cima para baixo, existindo nas sociedades ao menos uma parcela de normas cujo status de "jurídicas" advêm da espontaneidade dos costumes, e não de um ato deliberado de autoridade.

3. se a normatividade do direito advém de um hábito de obediência, então a teoria imperativa não consegue explicar a continuidade de ordens jurídicas, pois esse ato adquire caráter personalíssimo: morto o soberano habitualmente obedecido, não se torna sequer provável a obediência habitual ao seu sucessor, e, até que se estabeleça um novo hábito de obediência a esse segundo soberano, haverá um intervalo no qual nenhum direito existe. ${ }^{13}$

Assim, temos regras jurídicas que criam direitos e obrigações, fixando sanções, bem como regras que autorizam a produção de outras regras. 
E, é claro, temos também instituições que têm como função aplicar o Direito vigente em toda a sociedade. Dentre essas instituições, o Judiciário aparece como aquele que resolve os conflitos, fixando o sentido dos textos jurídicos de maneira final. Portanto, para entendermos o que é o Direito, é de fundamental importância que observemos o trabalho do Judiciário, até porque a regra não é o texto, mas a interpretação que se faz do texto jurídico. ${ }^{14}$

Pois bem. Os casos que podem chegar ao Judiciário podem ser casos fáceis ou casos difíceis. Nos casos fáceis, temos já uma solução dada pelo próprio texto jurídico, já que o mesmo não apresenta dificuldades de interpretação. Por outro lado, existem casos, embora excepcionais, em que ou o texto jurídico não é claro para resolver o problema, ou não existe texto jurídico que solucione o problema, ou, ainda, mais de um texto jurídico concorre para a solução do problema. E, agora, o que fazer?

Hart dirá que nesses casos difíceis o juiz deterá um poder discricionário para poder fixar o que é o Direito, independentemente dos textos jurídicos existentes, e isso pelo fato de que ninguém consegue saber com certeza o que o Direito ordena fazer. E o juiz poderá fazer isso, porque o próprio Direito e, no final das contas, a própria sociedade, autorizaram o Judiciário a assim agir nesses casos excepcionais. Existiria uma regra de reconhecimento socialmente difundida que permitira a práxis jurídica dos Tribunais, mesmo nesses casos em que o Direito não é claro e objetivo, inclusive para a continuidade do próprio Direito. ${ }^{15}$

Sintetizando o pensamento de Hart, pode-se dizer, seguindo os passos de Leonardo Figueiredo Barbosa ${ }^{16}$, que o filósofo britânico sustenta três teses centrais. A primeira, conhecida como tese das fontes sociais do direito, afirma que a existência e identificação do direito dependem da ocorrência de alguma prática social que determina, em diferentes sistemas jurídicos, quais são as fontes fundamentais, os critérios derradeiros ou os testes últimos de validade jurídica. É através dessa "regra última de um sistema" que se pode, de forma definitiva e concludente, identificar os aspectos ou características capazes de definir quais seriam as regras de direito que podem e devem ser consideradas como válidas em uma determinada organização social, ou seja, ela é o critério fundamental para a certificação da validade de uma regra jurídica. ${ }^{17}$ 
Como mostra Bruno Torrano, a regra de reconhecimento é talvez o aspecto mais obscuro do pensamento de Hart. Isso porque ao longo de sua obra, a regra de reconhecimento pode ser entendida como um "teste" de validade de todo o Direito, tendo levado à crítica de Ronald Dworkin sobre a questão; pode, ainda, a regra de reconhecimento ser compreendida como uma regra que confere poderes; ou, por fim, uma regra que impões deveres. ${ }^{18}$

Mas, afinal, qual é a melhor concepção de regra de reconhecimento no pensamento de Herbert Hart?

Nas palavras de Bruno Torrano:

Nesse cenário, a regra de reconhecimento hartiana surge como a norma secundária que, resolvendo o problema da incerteza do direito, determina em última análise quais regras jurídicas são vinculantes em uma dada comunidade. É, portanto, a norma que apõe em outras normas o selo da juridicidade. Essencialmente, a regra de reconhecimento pode ser compreendida como uma norma que se sustenta em uma aceitação dos oficiais do sistema a respeito de certos padrões de comportamento considerados como socialmente adequados, sendo ela própria a maneira correta de esclarecer dúvidas sobre a existência de uma regra jurídica vinculante. ${ }^{19}$ (Itálicos no original)

O grande problema está aí, pois Hart é obscuro e, muitas vezes, contraditório ao explicar a regra de reconhecimento. Daí porque ser possível compreender a regra de reconhecimento nas três acepções acima elencadas: como um "teste" de validade, uma regra que confere poderes ou uma regra que impõe deveres.

Para Bruno Torrano, a melhor compreensão da regra de reconhecimento é no sentido de ser uma regra que impõe deveres, ou seja, uma metanorma que obriga os oficiais do sistema jurídico a aplicarem normas que preencham certas características. Contudo, dizer que a regra de reconhecimento é uma regra que impõe deveres não elimina também sua característica de ser um teste de validade. Na medida em que obriga os oficiais a aplicarem as regras que preencham determinados requisitos, a regra de reconhecimento nada mais faz do que estabelecer os critérios da validade jurídica e, por isso, não pode deixar de ser vista como um teste de validade. ${ }^{20}$ 
A questão é saber se essa regra existe e se ela é necessária para a definição do conceito de Direito. Como defensores da teoria do Direito como Integridade de Ronald Dworkin, respondemos negativamente a essas duas questões.

Já a segunda tese de Hart é a denominada tese da discricionariedade jurídica, que significa que haveria casos não albergados pelas regras jurídicas, já que o direito é caracterizado pela finitude e incompletude. Além da possível ausência de regras, Hart admite que a incompletude do direito também possa derivar de limitações e indeterminações oriundas da própria linguagem humana, bem como da relativa ignorância de fato e a relativa indeterminação de finalidade, típicas de qualquer empreendimento que busca influenciar em comportamentos futuros, ocasionando o que o autor britânico denomina de textura aberta do direito. ${ }^{21}$

Por fim, a última tese de Hart é a que postula a separação conceitual entre direito e moral e significa que não existe relação necessária entre moralidade e legalidade, pois se é possível identificar o direito com base na observação neutra dessas regras que ocorrem na prática social, então existe diferença entre o que o direito é o que ele deveria ser, entre ética e direito, entre validade e justiça, embora possam existir conexões contingentes em determinadas comunidades entre direito e moral. Nesse sentido, a existência do direito é uma coisa; o seu mérito ou demérito, outra. ${ }^{22}$

Após toda a reconstrução da teoria do Direito de Herbert Hart, fica clara a conexão da teoria das fontes do Direito com a regra de reconhecimento proposta pelo autor positivista.

Isso porque cabe à regra de reconhecimento estabelecer o que é e o que não é Direito, tal como a teoria das fontes é responsável pela filtragem do que se torna Direito daquilo que não se torna.

Veremos, a seguir, que a teoria de Hart, como também a teoria das fontes do Direito compartilha do aguilhão semântico, tão bem denunciado por Ronald Dworkin. ${ }^{23}$

Remover o aguilhão semântico e, assim, conseguir enxergar o fenômeno jurídico à sua melhor luz, é o que propõe Dworkin. Acatando essa sugestão dworkiniana, como acreditamos que deva ser acatada, a concepção tradicional da teoria das fontes do Direito perde o sentido. 
É o que mostraremos a seguir.

\section{A TEORIA DO DIREITO COMO INTEGRIDADE E AS CRÍTICAS AO POSITIVISMO JURÍDICO E À TEORIA DAS FONTES DO DIREITO}

Nesse último tópico, mostraremos as críticas que Dworkin lança ao positivismo jurídico de Hart e como essas críticas são capazes de tanto mostrar o equívoco das teorias positivistas do Direito quanto da tradicional teoria das fontes do Direito.

Como mostramos nos tópicos anteriores, Hart pretende construir uma teoria que apenas descreva o fenômeno jurídico, a partir de uma perspectiva que ele denomina de externa.

Contudo, a partir do giro hermenêutico-pragmático na filosofia, representado por autores como Gadamer e Wittgenstein, já se pode questionar se tal empreitada será bem-sucedida, já que toda observação sempre parte de um ponto do qual o próprio observador faz parte. Assim, ao contrário do que pensa Hart, não há enunciados internos e externos que possam ser externamente observados. Além disso, o projeto de Hart é de uma descrição universal do que seja o Direito.

Dworkin se propõe exatamente questionar esses e outros postulados do positivismo de Hart. De acordo com Dworkin, sua teoria pretende ser uma teoria geral do direito e, para isso, deve articular uma parte normativa e conceitual. Portanto, não é apenas externa ou interna, mas o conjunto das duas coisas. ${ }^{24}$ Ainda de acordo com o autor, a parte normativa deve envolver não apenas o que as normas jurídicas postas significam, mas uma teoria moral, uma teoria filosófica, uma teoria da legitimidade das atuações dos poderes políticos, ou seja, a parte normativa da teoria jurídica está mesclada de pressupostos políticos, morais e filosóficos. Mais uma vez, a pretensão do positivismo de explicar o Direito apenas através do Direito não se sustenta, de acordo com Dworkin. ${ }^{25}$ Quanto à possibilidade de uma teoria jurídica que consiga explicar universalmente o Direito, Dworkin ${ }^{26}$ simplesmente afirma que sua teoria é uma teoria específica do Direito. Significa dizer que sua proposta pretende demonstrar e apresentar uma 
melhor teoria jurídica para os Estados Unidos da América. Em outras palavras, já se utilizando de uma perspectiva pragmatista, Dworkin revela que uma teoria deve ser adequada a um contexto.

Mas, afinal, como descrever (entendemos que toda descrição implica também levantar juízos de valor) de maneira adequada o Direito NorteAmericano ou Inglês? Será que a perspectiva de Hart no sentido de que o Direito é formado por um conjunto convencional de regras previamente estipuladas pelo Poder Legislativo ou outro órgão estatal é correta? E mais: será que é correta a perspectiva de Hart no sentido de que caso não haja uma regra explícita no ordenamento jurídico, os poderes públicos contariam com discricionariedade para resolver essa situação? ${ }^{27}$

De acordo com Dworkin ${ }^{28}$, a própria observação de Hart não leva a sério a própria prática jurídica nos Estados Unidos e na Inglaterra, revelando, mais uma vez, que toda observação não está isenta de pressupostos. Assim, no debate que o autor travará com Herbert L.A. Hart, mostrará que a prática jurídica é muito mais complexa do que aquela descrita por esse grande autor positivista. Na verdade, afirma Dworkin ${ }^{29}$, a teoria positivista de Hart não consegue descrever adequadamente o funcionamento do Direito, porque, ao contrário do que pensa Hart, os juízes, quando estão em face de questões controvertidas, não decidem essas questões de maneira livre e autônoma, criando Direito novo, mas tomam decisões vinculadas ao Direito existente. E isso acontece porque o Direito não é formado apenas pelos padrões normativos que Hart designa por regras, mas por princípios.

O problema da teoria de Hart e das teorias positivistas em geral se dá pelo fato de que elas compreendem o Direito apenas como uma questão de fato, se constituindo como teorias semânticas do Direito. Daí porque os positivistas compreenderem o Direito como um conjunto convencional de regras estabelecidas por uma autoridade do passado.

Para essas teorias: (1) o Direito é formado exclusivamente por um conjunto de regras, que podem ser diferenciadas das demais regras - por exemplo, as regras de natureza moral - por meio de um critério que, ironicamente, pode ser chamado de teste de pedigree da regra; ${ }^{30}(2)$ o conjunto de regras deve abranger, na maior medida possível, as relações jurídicas existentes em uma sociedade, mas no caso de lacuna - isto é, 
quando se está diante de um caso difícil -, o magistrado fica autorizado a decidir com base discricionária, inclusive indo além do Direito na busca desse novo padrão de orientação; e (3) na ausência de regra jurídica válida, compreende-se que não há obrigação jurídica; logo, quando o magistrado, no exercício de sua discricionariedade, decide um caso difícil, ele não está fazendo valer um direito correspondente à matéria controversa; ele está, sim, criando normas jurídicas. ${ }^{31}$

0 ataque às teorias semânticas - ou ao aguilhão semântico (semantic sting), como referido por Dworkin ${ }^{32}$ - dá-se por via da interpretação do Direito, ${ }^{33}$ ou melhor, por via da assunção de uma atitude interpretativa para com o Direito. Para explicar melhor essa tese, Dworkin ${ }^{34}$ parte do exemplo das "regras de cortesia", segundo as quais, por exemplo, os camponeses devem tirar seus chapéus quando estiverem diante dos nobres. Essas regras passariam por uma espécie de ciclo histórico, começando pela compreensão como se fosse um tabu. Portanto, a regra seria imutável e indiscutível. Todavia, em seguida, pode ser observado o começo de uma atitude interpretativa por parte dos membros daquela comunidade: em um primeiro momento, tem-se a compreensão de que não apenas a regra existe, mas apresenta uma finalidade; para, em seguida, compreenderem que as regras devem se adaptar a essa finalidade - desse modo, se tornam não apenas mutáveis, mas também interpretáveis - o que conduz ao fim de um processo de aplicação mecânica dessas regras de cortesia. ${ }^{35}$

Dessa forma, não é possível dissociar as práticas sociais - mesmo a aplicação de regras - de uma atitude interpretativa. Mas existem diversas formas de interpretação, podendo ser enunciadas outras formas, como: a conversacional, a científica e a artística. ${ }^{36}$

Assim,

A conversacional é intencional. Atribui significado a partir dos supostos motivos, intenções e preocupações do orador, e apresenta suas conclusões como afirmações sobre a interpretação deste ao dizer o que disse. A interpretação científica apresenta-se como uma interpretação causal, o cientista começa por coletar dados, para depois interpretá-los. A interpretação artística, por sua vez, tem por finalidade justificar um ponto de vista acerca do significado, tema ou propósito de determinada obra artística: um poema, uma peça ou uma pintura, etc., apresentando-se como uma interpretação construtiva, preocupada essencialmente com o propósito, não com a causa. 
Assim, do ponto de vista construtivo, a interpretação criativa é um caso de interação entre propósito e objeto. ${ }^{37}$

A partir desse esquema, portanto, é possível compreender que a interpretação das práticas sociais se assemelha mais à interpretação artística $^{38}$ - interpreta-se algo criado por pessoas, mas que representa uma entidade distinta delas $-{ }^{39}$ e é ainda uma forma de interpretação construtiva. Assim, ${ }^{40}$

Dworkin estabelece três etapas de interpretação, com a finalidade de tornar a interpretação construtiva instrumento apropriado ao estudo do direito enquanto prática social. Observe-se apenas que a perspectiva aqui é analítica, não havendo diferenciação em graus. Primeiro, de acordo com Dworkin, deve haver uma etapa pré-interpretativa, na qual são identificados as regras e os padrões que se considerem fornecer o conteúdo experimental da prática. Mesmo na etapa pré-interpretativa é necessário algum tipo de interpretação. Em segundo lugar, deve haver uma etapa interpretativa em que o intérprete se concentra numa justificativa geral para os principais elementos da prática identificada na pré-interpretativa. Isso vai consistir numa argumentação sobre a conveniência ou não de buscar uma prática com essa forma geral, raciocinar no sentido de buscar formar um pensamento sistemático sobre determinada matéria. A etapa pós-interpretativa ou reformuladora, a terceira e última etapa, consiste na etapa na qual o intérprete ajusta sua ideia daquilo que a prática "realmente" requer para melhor servir à justificativa que ele aceita na etapa interpretativa. ${ }^{41}$

Em acréscimo à ideia apresentada acima, tem-se a noção de paradigma jurídico, que complementa a interpretação construtiva. ${ }^{42}$ Apesar de mutáveis no tempo, os paradigmas buscam estabilizar a tensão entre realidade e idealidade, ${ }^{43}$ uma vez que fornecem o compartilhamento de uma determinada "percepção" pressuposta do Direito. ${ }^{44}$ Desse modo, paradigmas fixam interpretações, moldando a visão de uma comunidade a ele submetida, de tal modo que a rejeição a um paradigma, muitas vezes, pode ser lida por essa comunidade como um erro extraordinário.

O Direito - como um conceito interpretativo - exige, portanto, por parte da comunidade, um consenso inicial no sentido de estabelecer quais práticas sociais são consideradas jurídicas (nível pré-interpretativo). ${ }^{45}$ Nessa perspectiva, pode-se compreender como Direito o "sistema de direitos 
e responsabilidade que respondem a [um] complexo padrão: autorizam a coerção porque decorre de decisões anteriores do tipo adequado" ${ }^{\prime 4}$. Todavia, esse conceito é provisório. Ele levanta uma exigência no sentido de proceder a uma análise mais detalhada de três concepções ${ }^{47}$ do Direito: ${ }^{48}$ o convencionalismo, o pragmatismo e o Direito como integridade.

O convencionalismo ${ }^{49}$ pode ter a sua tese central apresentada da seguinte forma:

[...] a força coletiva só deve ser usada contra o indivíduo quando alguma decisão política do passado assim o autorizou explicitamente, de tal modo que advogados e juízes competentes estarão todos de acordo sobre qual foi a decisão, não importa quais sejam suas divergências em moral e política. ${ }^{50}$

Nessa leitura, o Direito é dependente de convenções sociais que irão determinar quais instituições gozam do poder de elaborar as leis e como elas podem fazer isso. Tudo estaria resumido ao respeito às convenções do passado e a sua aplicação, considerando a conclusão a que chegaram e nada mais. Mesmo assim, tal concepção reconhece que não haverá um Direito completo, capaz de abarcar toda a complexidade da vida social, uma vez que reconhece a possibilidade de que novos problemas apareçam. A solução, portanto, passa pela afirmação da discricionariedade do magistrado no momento de aplicação jurídica: uma vez que se reconhece que nenhuma das partes titulariza direitos capazes de amparar suas pretensões - já que os únicos direitos que podem contar são aqueles previamente fixados pelas convenções - os juízes devem encontrar alguma outra forma de justificativa, para além do Direito, que apoie a decisão a ser tomada; todavia a questão continua por demais aberta, assim eles poderão pautar-se por questões abstratas de justiça, ou questões que se refiram ao interesse coletivo, ou mesmo uma justificativa que se volte para o futuro.

Daí extraem-se duas afirmativas pós-interpretativas do convencionalismo, a de que os juízes devem respeitar as convenções jurídicas em vigor em sua comunidade, a não ser em raras circunstâncias; e a de que não existe direito a não ser aquele que é extraído de tais decisões por meio de técnicas que são, elas próprias, questões de convenção, e que, portanto, em alguns casos não existe direito. Neste caso, devem os juízes exercitar o seu 
poder discricionário, utilizando padrões extrajurídicos para fazer o que o convencionalismo considera ser um novo direito. Ao decidirem discricionariamente, os juízes convencionalistas criam novo direito aplicável de forma retroativa às partes envolvidas no caso. ${ }^{51}$

Dworkin ${ }^{52}$ lembra que a concepção convencionalista apresenta distinções em relação às teorias semântico-positivistas, que, por serem uma teoria interpretativa, não fazem uso de um critério linguístico para identificar o que é o Direito. No entanto, essas últimas apresentam um traço de semelhança com a Teoria do Direito como integridade, que é justamente o fato de ambas considerarem importantes as decisões tomadas no passado para o processo de compreensão dos direitos presentes. Mas será justamente no modo como consideram essas decisões passadas que se encontra o seu traço distintivo.

O convencionalismo fracassa como interpretação da prática jurídica em função do seu aspecto negativo - isto é, ao afirmar que "[...] não existe direito a não ser aquele que é extraído de decisões por meio de técnicas que são, elas próprias, questões de convenção" 53 . Esse fracasso decorre do fato de os magistrados se tornarem mais dedicados às fontes convencionais (legislação e precedentes) do que lhes permite o convencionalismo.

Um juiz consciente de seu convencionalismo estrito perderia o interesse pela legislação e pelo precedente exatamente quando ficasse claro que a extensão explícita dessas supostas convenções tivesse chegado ao fim. Ele então entenderia que não existe direito, e deixaria de preocupar-se com a coerência com o passado; passaria a elaborar um novo direito, indagando qual lei estabeleceria a legislatura em vigor, qual é a vontade popular ou o que seria melhor para os interesses da comunidade no futuro. ${ }^{54}$

Todavia, esse novo direito deverá guardar uma coerência com a legislatura do passado. É justamente essa busca por coerência que pode explicar a preocupação com o passado. Dworkin identifica duas formas de coerência: coerência de estratégia e coerência de princípio. A primeira diz respeito à preocupação que qualquer um deve ter ao criar um novo direito, no sentido de que esse se ajuste ao que foi estabelecido, ou ao que venha a ser no futuro; o conjunto de regras deve funcionar conjuntamente, tornando a situação melhor. Já a coerência de princípio representa uma 
exigência de que os "[...] diversos padrões que regem o uso estatal da coerção contra os cidadãos seja coerente no sentido de expressaram uma visão única e abrangente da justiça" ${ }^{55} .56$ É neste ponto que o convencionalismo mostra-se divergente da concepção do Direito como integridade: esta aceita a coerência de princípio como uma fonte de direitos, aquele não:

[...] o direito como integridade supõe que as pessoas têm direitos - direitos que decorrem de decisões anteriores de instituições políticas, e que, portanto, autorizam a coerção - que extrapolam a extensão explícita das práticas políticas concebidas como convenções. 0 direito como [integridade] supõe que as pessoas têm direitos a uma extensão coerente, e fundada em princípios, das decisões políticas do passado, mesmo quando os juízes divergem profundamente sobre seu significado. Isso é negado pelo convencionalismo: um juiz convencionalista não tem razões para reconhecer a coerência de princípio como uma virtude judicial, ou para examinar minuciosamente leis ambíguas ou precedentes inexatos para tentar alcançá-la. ${ }^{57}$

Um crítico do convencionalismo, como no caso do jurista de Oxford, deve ainda aclarar duas questões: (1) o pressuposto convencionalista segundo o qual qualquer consenso alcançado deve ser visto como uma questão de convenção ou como uma questão de convicção; e (2) a questão referente à segurança jurídica. Dworkin responde a essa primeira pergunta através de uma analogia com o jogo de xadrez: ${ }^{58}$ No jogo, as regras são estabelecidas por meio de convenção e, no Direito, por meio de convicção, entendida essa como a necessidade de buscar uma fundamentação das práticas sociais à luz de uma teoria política. Por isso, no caso do convencionalismo,

[o] consenso que estabelece determinada convenção independe da convicção acerca do valor intrínseco de determinada regra, ou seja, uma proposição específica sobre a legislação, tida como verdadeira por convenção, prescinde de uma razão substantiva para a sua aceitação. Se o consenso é de convicção, qualquer ataque contra o seu argumento substantivo será um ataque contra a própria proposição. 0 consenso, de acordo com Dworkin, só vai durar enquanto a maioria dos juristas aceitar as convicções que o sustentam. ${ }^{59}$

E aqui percebe-se o fracasso da pretensão levantada pelos convencionalistas: a convenção não é imprescindível ao Direito, bastando 
que o nível de acordo de convicção seja alto o bastante em um momento dado para se permitir que o debate sobre as práticas jurídicas possa ter continuidade. ${ }^{60}$ Além disso, uma análise das práticas pode demonstrar que os juízes, ao decidirem, tratam as técnicas de interpretação das leis e de avaliação de precedentes como princípios - e não como legados de uma tradição. Por isso mesmo, eles se apoiam em alguma teoria política mais profunda. Quando acham que essa teoria política não é mais suficiente, eles elaboram teorias que lhes pareçam melhores. ${ }^{61}$

Quanto ao segundo problema (segurança jurídica), Dworkin afirma que a previsibilidade que o convencionalismo alega conseguir é ilusória, pois a discricionariedade, que constitui uma premissa interna a essa concepção, coloca em cheque a possibilidade de estabilidade; a expectativa social de segurança (previsibilidade) projetada pelo convencionalismo se desvanece completamente diante da subjetividade judicial. ${ }^{62}$

Portanto, se compreendemos o Direito como um conceito interpretativo e não como uma questão de fato, retiramos o aguilhão semântico e mostramos que o problema da compreensão, intepretação e aplicação do Direito não se encontra em revelar uma convenção estabelecida no passado, tal como querem os positivistas e a própria teoria das fontes do Direito.

A questão passa a ser mais profunda e complexa. Se o Direito é uma prática social interpretativa em que a própria comunidade de princípios vai construindo o Direito que regerá sua própria vida, reconhecendo-se como uma comunidade dotada de iguais liberdades, então o Direito já não se esgota em um conjunto de regras fixas, localizáveis em algum lugar, em alguma fonte.

Afinal, ao contrário do que o positivismo jurídico acreditava, o Direito só é concretizado no momento da aplicação normativa, em face do caso concreto, algo que não pode ser revelado "a priori” por qualquer fonte. Daí porque, para um Direito principiológico tal como concebido no Brasil, não deveria mais fazer sentido pretender que certas fontes revelem, antecipadamente, o que seja o Direito.

No atual contexto, muito mais importante são as práticas sociais interpretativas que busquem mostrar o nosso Direito à sua melhor luz, ou seja, que mostrem o fenômeno jurídico como um processo dinâmico 
e permanente de afirmação das iguais liberdades de todos os membros de nossa comunidade, à luz de cada caso concreto e com base em argumentos constitucionalmente adequados à luz do paradigma do Estado Democrático de Direito.

\section{CONCLUSÃO}

Pretendemos defender, nesse texto, que a teoria do ordenamento jurídico deve ser repensada se compreendermos o sistema jurídico como um conjunto coerente de princípios, tal como defendido por Ronald Dworkin.

Nesse sentido, ao longo do presente trabalho, demonstramos como a teoria das fontes, tal como ainda tradicionalmente ensinada nos livros jurídicos e nos Cursos de Direito em nosso país, encontra-se presa ao aguilhão semântico, expressão popularizada por Dworkin em seu debate com o positivismo de Hart.

Assim, a teoria das fontes do Direito compartilha com o positivismo jurídico a crença, equivocada, no sentido de que o Direito é um conjunto convencional de regras estabelecidas por alguma autoridade do passado, existindo um padrão, uma regra de reconhecimento, que determina quando uma regra é jurídica e quando ela faz parte de outro domínio normativo.

A partir das críticas lançadas por Ronald Dworkin ao positivismo jurídico de Herbert Hart, conseguimos mostrar que o Direito se apresenta como algo muito mais complexo do que apenas um conjunto de regras estabelecidas em algum momento do passado: o Direito é uma questão de princípio e princípios decorrem das práticas interpretativas da própria comunidade que se vê como autora e destinatária das normas que regem suas próprias vidas dentro dessa comunidade.

Nesse sentido, a teoria das fontes do Direito precisa ser abandonada, devendo-se reconhecer que não existem padrões sociais fixos a determinar quando um texto normativo é jurídico ou não. Afinal, o Direito é um conceito interpretativo e não criterial, ou seja, não se resume a um conjunto de critérios previamente determinados por alguma autoridade. Assim, a teoria das fontes do Direito se torna imprestável para quem compreende o Direito como um conjunto íntegro e coerente de princípios 
que devem ser compreendidos, interpretados e aplicados à sua melhor luz, respeitando-se a história institucional da comunidade e os direitos morais de seus membros.

\section{NOTAS}

1 DIMOULIS, Dimitri. Manual de Introdução ao Estudo do Direito. $7^{a}$ edição, revista, atualizada e ampliada, São Paulo: Revista dos Tribunais, 2016, p. 170 e seguintes.

2 HART, H.L.A. O Conceito de Direito. São Paulo: Martins Fontes, 2009.

3 DIMOULIS, Dimitri. Manual de Introdução ao Estudo do Direito. $7^{\text {a }}$ edição, revista, atualizada e ampliada, São Paulo: Revista dos Tribunais, 2016, p. 170.

4 BUSTAMANTE, Thomas da Rosa. 0 direito e a incerteza de suas fontes: um problema em aberto para a dogmática jurídica contemporânea. Revista da Faculdade de Direito da UFMG. Número Especial: Jornadas Jurídicas Brasil-Canadá, pp. 303-304, 2013.

5 DIMOULIS, Dimitri. Manual de Introdução ao Estudo do Direito. $7^{a}$ edição, revista, atualizada e ampliada, São Paulo: Revista dos Tribunais, 2016, p. 170.

6 DIMOULIS, Dimitri. Manual de Introdução ao Estudo do Direito. $7^{\mathrm{a}}$ edição, revista, atualizada e ampliada, São Paulo: Revista dos Tribunais, 2016, p. 171.

7 DIMOULIS, Dimitri. Manual de Introdução ao Estudo do Direito. $7^{a}$ edição, revista, atualizada e ampliada, São Paulo: Revista dos Tribunais, 2016, p. 171.

8 BUSTAMANTE, Thomas da Rosa. 0 direito e a incerteza de suas fontes: um problema em aberto para a dogmática jurídica contemporânea. Revista da Faculdade de Direito da UFMG. Número Especial: Jornadas Jurídicas Brasil-Canadá, p. 306.

9 DWORKIN, Ronald. Levando os Direitos a Sério. São Paulo: Martins Fontes, 2002.

10 HART, H.L.A. 0 Conceito de Direito. São Paulo: Martins Fontes, 2009, p. IX.

11 Sobre a diversidade de positivismos jurídicos, vide: TORRANO, Bruno e OMMATI, José Emílio Medauar.(Coordenadores). O Positivismo Jurídico no Século XXI. Coleção Teoria Crítica do Direito. Volume 5. Rio de Janeiro: Lumen Juris, 2018.

12 HART, H. L.A. O Conceito de Direito. São Paulo: Martins Fontes, 2009.

13 TORRANO, Bruno. Democracia e Respeito à Lei: Entre Positivismo Jurídico e Pós-Positivismo. Rio de Janeiro: Lumen Juris, 2015, p. 34.

14 HART, H. L.A. 0 Conceito de Direito. São Paulo: Martins Fontes, 2009.

15 HART, H. L.A. O Conceito de Direito. São Paulo: Martins Fontes, 2009.

16 BARBOSA, Leonardo Figueiredo. Pressupostos Teóricos e Questões Metodológicas Relevantes no Debate Hart-Dworkin. IN: CUNHA, José Ricardo(Organizador). Epistemologias Críticas do Direito. Rio de Janeiro: Lumen Juris, 2016, p. 377 a 378.

17 BARBOSA, Leonardo Figueiredo. Pressupostos Teóricos e Questões Metodológicas Relevantes no Debate Hart-Dworkin. Op.cit. IN: CUNHA, José Ricardo(Organizador). Epistemologias Críticas do Direito. Rio de Janeiro: Lumen Juris, 2016, p. 377.

18 TORRANO, Bruno. Do Fato à Legalidade: Introdução à Teoria Analítica do Direito. Rio de Janeiro: Lumen Juris, 2014, p. 129 a 131.

19 TORRANO, Bruno. Do Fato à Legalidade: Introdução à Teoria Analítica do Direito. Rio de Janeiro: Lumen Juris, 2014, p. 129.

20 TORRANO, Bruno. Do Fato à Legalidade: Introdução à Teoria Analítica do Direito. Rio de Janeiro: Lumen Juris, 2014, p. 131.

21 BARBOSA, Leonardo Figueiredo. Pressupostos Teóricos e Questões Metodológicas Relevantes no Debate Hart-Dworkin. IN: CUNHA, José Ricardo(Organizador). Epistemologias Críticas do Direito. Rio de Janeiro: Lumen Juris, 2016, p. 378.

22 BARBOSA, Leonardo Figueiredo. Pressupostos Teóricos e Questões Metodológicas Relevantes no Debate Hart-Dworkin. IN: CUNHA, José Ricardo(Organizador). Epistemologias Críticas do Direito. Rio de Janeiro: Lumen Juris, 2016, p. 378. 
23 DWORKIN, Ronald. O Império do Direito. São Paulo: Martins Fontes, 1999.

24 DWORKIN, Ronald. Levando os Direito a Sério. São Paulo: Martins Fontes, 2002, p. VIII.

25 DWORKIN, Ronald. Levando os Direito a Sério. São Paulo: Martins Fontes, 2002, p. VIII a IX.

26 DWORKIN, Ronald. Levando os Direito a Sério. São Paulo: Martins Fontes, 2002, p. XIX.

27 HART, H.L.A. 0 Conceito de Direito. São Paulo: Martins Fontes, 2009.

28 DWORKIN, Ronald. O Império do Direito. São Paulo: Martins Fontes, 1999.

29 DWORKIN, Ronald. O Império do Direito. São Paulo: Martins Fontes, 1999.

30 Tomando como base a teoria de Austin, Dworkin mostra que o teste de pedigree seria a afirmação de que o Direito é aquilo que o soberano diz ser; correspondentemente, na tese sustenta por Hart, a regra de conhecimento desempenhará esse papel. Apesar de silente no texto, ao lançar um olhar sobre a teoria kelseniana, pode-se concluir que a norma fundamental seria a candidata ao teste.

31 Para tanto, basta observar a postura assumida por Kelsen, em sua Teoria Pura do Direito, afirmando que a decisão do tribunal é discricionária, mas permaneceria como jurídica desde que estivesse incluída dentro da moldura de interpretações possíveis(KELSEN, Hans. Teoria Pura do Direito. 6. ed. Trad. João Batista Machado. São Paulo: Martins Fontes, 1999. p. 390). Contudo, após a edição de 1960, Kelsen dá uma guinada completamente diferente em sua teoria - um giro decisionista, ao admitir que o tribunal possa escolher uma interpretação que se situe fora dessa moldura interpretativa (KELSEN, Hans. Teoria Pura do Direito. 6. ed. Trad. João Batista Machado. São Paulo: Martins Fontes, 1999. p. 392-395). Como bem afirma Cattoni de Oliveira (CATTONI DE OLIVEIRA, Marcelo Andrade. Direito processual constitucional. Belo Horizonte: Mandamentos, 2001. p. 51), tal posicionamento coloca em "pane" a teoria kelseniana, pois rompe com o postulado metodológico da separação entre teoria e sociologia do Direito.

32 DWORKIN, Ronald. O Império do Direito. São Paulo: Martins Fontes, 1999. p. 55.

33 Como lembra Araújo (ARAÚJO, Marcelo Cunha. “O Império do Direito” de Ronald Dworkin. Revista da Faculdade Mineira de Direito. Belo Horizonte: PUC Minas. v. 4. n. 7 e 8, jan./jun. 2001. p. 121), Dworkin pretende superar o seguinte dilema: “Ou advogados, apesar das aparências, realmente aceitam, em linha gerais, os mesmos critérios para decidir quando uma afirmação sobre o direito é verdadeira, ou não pode existir absolutamente nenhum verdadeiro acordo ou desacordo sobre o que é o direito" (DWORKIN, Ronald. O Império do Direito. São Paulo: Martins Fontes, 1999. p. 56.). Dworkin (DWORKIN, Ronald. O Império do Direito. São Paulo: Martins Fontes, 1999. p. 55.) explica que seria razoável uma discussão somente quando se tratar de casos limítrofes para exemplificar, ele transporta a questão para o universo literário: pode-se discutir se tal obra se trata de um livrinho ou um panfleto, todavia não podemos estar em desacordo quanto a se Moby Dick é ou não livro, apenas porque, na opinião pessoal de um dos debatedores, esse não considera romance uma forma de livro. A solução, então, está na convergência das afirmações que não necessita ser total em todas as fases da interpretação.

34 DWORKIN, Ronald. O Império do Direito. São Paulo: Martins Fontes, 1999. p. 57.

35 "Quando essa atitude interpretativa passa a vigorar, a instituição da cortesia deixa de ser mecânica; não é mais a deferência espontânea a uma ordem rúnica. As pessoas agora tentam impor um significado à instituição - vê-la em sua melhor luz - e, em seguida, reestruturá-la à luz desse significado" (DWORKIN, Ronald. O Império do Direito. São Paulo: Martins Fontes, 1999. p. 58.).

36 ARAÚJO, Marcelo Cunha. “O Império do Direito” de Ronald Dworkin. Revista da Faculdade Mineira de Direito. Belo Horizonte: PUC Minas. v. 4. n. 7 e 8, jan./jun. 2001. p. 121.

37 LAGES, Cíntia Garabini. A proposta de Ronald Dworkin em “O Império do Direito”. Revista da Faculdade Mineira de Direito. Belo Horizonte: PUC Minas. v. 4 . n. 7 e 8, jan./jun. 2001. p. 39, grifos nossos.

38 A partir da exigência da interpretação artística de tratar o objeto ou prática como o melhor possível, todavia, não decorre a afirmação de que o intérprete poderá fazer ou compreender o que bem quiser, pois lembrando o princípio gadameriano da história efetual, tem-se que "[...] a história ou a forma de uma prática ou objeto exerce uma coerção sobre as interpretações disponíveis destes últimos [...]" (DWORKIN, Ronald. O Império do Direito. São Paulo: Martins Fontes, 1999. p. 64.). Vale, ainda, lembrar que a experiência artística é, também, para Gadamer uma referência importante. Desse modo, o autor faz uso dela para iniciar a explicação sobre a experiência hermenêutica: "A obra de arte tem, antes, o seu verdadeiro ser em se tornar uma 
experiência que irá transformar aquele que a experimenta. 0 'sujeito' da experiência da arte, o que fica e persevera, não é a subjetividade de que a experimenta, mas a própria obra de arte" (GADAMER, Hans-Georg. Verdade e método: Fundamentos de uma hermenêutica filosófica. 3. ed. Petrópolis: Vozes, 2001. p. 32).

39 Algumas teorias da interpretação jurídica, contudo, ainda parecem ter como referência a interpretação conversacional, remontando ao pensamento da hermenêutica pré-gadameriana ou aos estudos de Betti. Assim, essa tese compreende mal, como já visto, a própria atividade de interpretação: no caso das práticas sociais, portanto, a atividade de interpretação deve sim conduzir a uma construção do melhor objeto possível, isto é, identificar uma interpretação que melhor satisfaça a finalidade da regra; não pode, portanto, se limitar a busca da intenção do autor - como querem os originalistas, principalmente, no Direito norte-americano -, como forma de garantia de objetividade da interpretação, ainda assim, essa busca se pautaria por escolhas que o intérprete fez no sentido de compreender melhor o seu objeto, o que nada mais é do que a aplicação da interpretação construtiva; por fim, não se pode nem tomar uma prática social como uma obra de um autor determinado, nem atribuí-la a ninguém, e com isso, lançar mão de uma interpretação científica, pois uma prática social para ser compreendida exige uma atitude interna, condizente com a condição de um participante dessa prática, não havendo lugar para uma simples descrição (DWORKIN, Ronald. Hart's Postscript and the character of Political Philosophy. Oxford Journal of Legal Studies. Oxford: Oxford University. v. 24. n. 1. 2004. p. 5).

40 LAGES, Cíntia Garabini. A proposta de Ronald Dworkin em “O Império do Direito". Revista da Faculdade Mineira de Direito. Belo Horizonte: PUC Minas. v. 4. n. 7 e 8, jan./jun. 2001. p. 40.

41 Araújo (ARAÚJO, Marcelo Cunha. “O Império do Direito” de Ronald Dworkin. Revista da Faculdade Mineira de Direito. Belo Horizonte: PUC Minas. v. 4. n. 7 e 8, jan./jun. 2001. p. 122) e Souza Cruz (SOUZA CRUZ, Álvaro Ricardo de. Privilégio de foro e improbidade administrativa. In: SOUZA CRUZ, Álvaro Ricardo de (coord.). 0 Supremo Tribunal Federal Revisitado: o ano judiciário de 2002. Belo Horizonte: Mandamentos, 2003. p. 31), apresentam excelentes esquemas, que podem ser tomados como complementares a esse. Segundo este último autor, através da interpretação construtiva Dworkin supera o aguilhão semântico inerente ao positivismo, "[...] uma vez que percebe haver elemento de mutação temporal no conceito interpretativo do Direito, próprio do ciclo paradigmático. Em outras palavras, a comunidade jurídica não possui um conjunto uniforme de compreensões sobre as proposições jurídicas, mas, ao contrário, tais compreensões se modificam à medida que a sociedade se modifica também".

42 DWORKIN, Ronald. O Império do Direito. São Paulo: Martins Fontes, 1999. p. 88-89.

43 CATTONI DE OLIVEIRA, Marcelo Andrade. Teoria discursiva da argumentação jurídica de aplicação e garantia processual jurisdicional dos direitos fundamentais. Revista brasileira de estudos políticos. Belo Horizonte. n. 88. dez./2003. p. 119.

44 Sobre do que se entende por paradigma e "paradigmas jurídicos" vide: PEDRON, Flávio Quinaud e OMMATI, José Emílio Medauar. Teoria do Direito Contemporânea: Uma Análise das Teorias Jurídicas de Robert Alexy, Ronald Dworkin, Jürgen Habermas, Klaus Günther e Robert Brandom. Rio de Janeiro: Lumen Juris, 2019.

45 Em sentido contrário, para o aguilhão semântico, a identificação dessas práticas acontece por meio de uma definição comum daquilo que necessariamente configura um sistema jurídico, bem como das instituições que o constituem. Sobre isso ver: (1) DWORKIN, Ronald. 0 Império do Direito. São Paulo: Martins Fontes, 1999. p. 114.; (2) (ARAÚJO, Marcelo Cunha. “O Império do Direito" de Ronald Dworkin. Revista da Faculdade Mineira de Direito. Belo Horizonte: PUC Minas. v. 4 . n. 7 e 8, jan./jun. 2001. p. 123).

46 DWORKIN, Ronald. 0 Império do Direito. São Paulo: Martins Fontes, 1999. p. 116.

47 Deve-se atentar para a distinção dworkiniana entre os termos concepção e conceito: "o contraste entre conceito e concepção é aqui um contraste entre níveis de abstração nos quais se pode estudar a interpretação da prática" (DWORKIN, Ronald. O Império do Direito. São Paulo: Martins Fontes, 1999. p. 87.). Nessa lógica, tem-se que um conceito possuiria um conteúdo aberto que admite diferentes concepções, segundo uma perspectiva tomada. Falar em teoria sobre o conceito de Direito seria um retorno à tese semântica que justamente pretende ser combatida; a concepção de Direito, portanto, não está pautada sob regras básicas da linguagem de observa- 
ção obrigatórias a todos que desejam fazer-se entender, mas antes disso, em uma compreensão interpretativa, temporal, que se mantém graças a um padrão de acordo e desacordo.

48 "As concepções do direito aprimoram a interpretação inicial e consensual que [...] proporciona nosso conceito de direito. Cada concepção oferece as respostas relacionadas a três perguntas colocadas pelo conceito. Primeiro, justifica-se o suposto elo entre o direito e a coerção? Faz algum sentido exigir que a força pública seja usada somente em conformidade com os direito e responsabilidade que 'decorrem' de decisões políticas anteriores? Segundo, se tal sentido existe, qual é ele? Terceiro, que leitura de 'decorrer' - que noção de coerência com decisões precedentes - é a mais apropriada? A resposta que uma concepção dá a essa terceira pergunta determina os direitos e responsabilidade jurídicos concretos que reconhece" (DWORKIN, Ronald. O Império do Direito. São Paulo: Martins Fontes, 1999. p. 117-118.).

49 Dworkin (DWORKIN, Ronald. O Império do Direito. São Paulo: Martins Fontes, 1999. p. 152.) identifica dois tipos de convencionalismo: estrito e moderado. 0 "convencionalismo estrito restringe a lei de uma comunidade à extensão explícita de suas convenções jurídicas, como a legislação e o precedente" (LAGES, Cíntia Garabini. A proposta de Ronald Dworkin em "O Império do Direito". Revista da Faculdade Mineira de Direito. Belo Horizonte: PUC Minas. v. 4 . n. 7 e 8 , jan./jun. 2001. p. 42). Trata-se de uma concepção bastante restrita do Direito. Por outro lado, o convencionalismo moderado compreende o Direito de uma comunidade como incluindo tudo o que estiver dentro da extensão - mesmo que implicitamente - das convenções. Desse modo, o convencionalismo estrito declara a existência de uma lacuna e requer o exercício do poder discricionário do juiz - que por meio de padrões extrajurídicos, cria um novo direito. Para o convencionalismo moderado, não haveria necessidade de declarar a existência da lacuna; ainda que de maneira polêmica, afirma que há uma maneira "correta" de interpretar as convenções abstratas, de modo que elas possam responder a qualquer caso que surja (DWORKIN, Ronald. 0 Império do Direito. São Paulo: Martins Fontes, 1999. p. 155.). Sob essa ótica, então, o convencionalismo moderado - que é assumido por Hart - pode-se mostrar como uma forma subdesenvolvida da tese do Direito como integridade - já que "não garante e nem mesmo promove o ideal das expectativas asseguradas, segundo o qual as decisões do passado somente serão tomadas por base para justificar a força coletiva quando sua autoridade e seus termos forem inquestionáveis sob a perspectiva das convenções amplamente aceitas (LAGES, Cíntia Garabini. A proposta de Ronald Dworkin em “O Império do Direito". Revista da Faculdade Mineira de Direito. Belo Horizonte: PUC Minas. v. 4. n. 7 e 8, jan./jun. 2001. p. 42). Dessa forma, apenas o convencionalismo estrito será objeto das críticas de Dworkin.

50 DWORKIN, Ronald. O Império do Direito. São Paulo: Martins Fontes, 1999. p. 141. (Coleção Direito e Justiça).

51 LAGES, Cíntia Garabini. A proposta de Ronald Dworkin em "O Império do Direito". Revista da Faculdade Mineira de Direito. Belo Horizonte: PUC Minas. v. 4. n. 7 e 8, jan./jun. 2001. p. 41.

52 DWORKIN, Ronald. O Império do Direito. São Paulo: Martins Fontes, 1999. p. 143 a 144.

53 LAGES, Cíntia Garabini. A proposta de Ronald Dworkin em "O Império do Direito". Revista da Faculdade Mineira de Direito. Belo Horizonte: PUC Minas. v. 4. n. 7 e 8, jan./jun. 2001. p. 42.

54 DWORKIN, Ronald. O Império do Direito. São Paulo: Martins Fontes, 1999. p. 159.

55 LAGES, Cíntia Garabini. A proposta de Ronald Dworkin em "O Império do Direito". Revista da Faculdade Mineira de Direito. Belo Horizonte: PUC Minas. v. 4. n. 7 e 8, jan./jun. 2001. p. 43.

56 "Um juiz quevisa à coerência de princípio se preocuparia, de fato, como os juízes de nossos exemplos, com os princípios que seria preciso compreender para justificar leis e procedentes do passado" DWORKIN, Ronald. O Império do Direito. São Paulo: Martins Fontes, 1999. p. 163 a 164.

57 DWORKIN, Ronald. O Império do Direito. São Paulo: Martins Fontes, 1999. p. 164.

58 Dworkin (DWORKIN, Ronald. O Império do Direito. São Paulo: Martins Fontes, 1999. p. 167 a 168.) reconhece que, com o passar dos tempos, as regras de um jogo podem sofrer mudanças; mesmo assim, há uma diferença quando essas regras foram aceitas como uma convenção. "Se um congresso mundial de xadrez se reunisse para reconsiderar as regras para os torneios futuros, os argumentos apresentados em tal congresso estariam claramente deslocados dentro de um jogo de xadrez, e vice-versa. Talvez o xadrez fosse mais estimulante e interessante se as regras fossem mudadas de modo a permitir que o rei avançasse duas casas em cada lance. Mas 
ninguém que pensasse assim traria a sugestão como um argumento de que o rei pode agora, como o determinam as regras, avançar duas casas por vez. Por outro lado, mesmo durante o jogo, os advogados muitas vezes pedem por mudanças de práticas estabelecidas. Alguns dos mais antigos argumentos que as intenções legislativas levam em conta foram apresentados a juízes no decorrer de processos. Importantes mudanças na doutrina do precedente também foram feitas no decorrer do jogo: juízes foram convencidos, ou se convenceram eles próprios, de que na verdade não estavam presos às decisões que seus predecessores haviam considerado obrigatórias. [...] não foram o resultado de acordos especiais com a finalidade de chegar a uma nova série de convenções" (DWORKIN, Ronald. O Império do Direito. São Paulo: Martins Fontes, 1999. p. 168).

59 LAGES, Cíntia Garabini. A proposta de Ronald Dworkin em "O Império do Direito". Revista da Faculdade Mineira de Direito. Belo Horizonte: PUC Minas. v. 4. n. 7 e 8, jan./jun. 2001. p. 43.

60 "A atitude interpretativa precisa de paradigmas para funcionar efetivamente, mas estes não precisam ser questões de convenção. Será suficiente que o nível de acordo de convenção seja alto o bastante em qualquer momento dado, para permitir que o debate sobre práticas fundamentais como a legislação e o precedente possa prosseguir da maneira como descrevi no segundo capítulo, contestando os diferentes paradigmas um por um, como a reconstrução do barco de Neurath no mar, prancha por prancha" DWORKIN, Ronald. O Império do Direito. São Paulo: Martins Fontes, 1999. p. 169.

61 DWORKIN, Ronald. O Império do Direito. São Paulo: Martins Fontes, 1999. p. 169.

62 SOUZA CRUZ, Álvaro Ricardo de. Privilégio de foro e improbidade administrativa. In: SOUZA CRUZ, Álvaro Ricardo de (coord.). 0 Supremo Tribunal Federal Revisitado: o ano judiciário de 2002. Belo Horizonte: Mandamentos, 2003. p. 34.

\section{REFERÊNCIAS}

ARAÚJO, Marcelo Cunha. "O Império do Direito" de Ronald Dworkin. Revista da Faculdade Mineira de Direito. Belo Horizonte: PUC Minas. v. 4. n. 7 e 8, jan./ jun. 2001.

BARBoSA, Leonardo Figueiredo. Pressupostos Teóricos e Questões Metodológicas Relevantes no Debate Hart-Dworkin. IN: CUNHA, José Ricardo (Organizador). Epistemologias Críticas do Direito. Rio de Janeiro: Lumen Juris, 2016.

BUSTAMANTE, Thomas da Rosa. 0 direito e a incerteza de suas fontes: um problema em aberto para a dogmática jurídica contemporânea. Revista da Faculdade de Direito da UFMG. Número Especial: Jornadas Jurídicas BrasilCanadá, 2013, pp. 299-325.

CATTONI DE OLIVEIRA, Marcelo Andrade. Direito processual constitucional. Belo Horizonte: Mandamentos, 2001.

CATTONI DE OLIVEIRA, Marcelo Andrade. Teoria discursiva da argumentação jurídica de aplicação e garantia processual jurisdicional dos direitos 
fundamentais. Revista brasileira de estudos políticos. Belo Horizonte. $\mathrm{n}$. 88. dez./2003.

DIMOULIS, Dimitri. Manual de Introdução ao Estudo do Direito. $7^{\mathrm{a}}$ edição, revista, atualizada e ampliada, São Paulo: Revista dos Tribunais, 2016.

DWORKIN, Ronald. Hart's Postscript and the character of Political Philosophy. Oxford Journal of Legal Studies. Oxford: Oxford University. v. 24. n. 1. 2004.

DWORKIN, Ronald. Levando os Direitos a Sério. São Paulo: Martins Fontes, 2002.

DWORKIN, Ronald. 0 Império do Direito. Trad. Jefferson Luiz Camargo. São Paulo: Martins Fontes, 1999.

GADAMER, Hans-Georg. Verdade e método: Fundamentos de uma hermenêutica filosófica. 3. ed. Trad. Enio Paulo Giachini. Petrópolis: Vozes, 2001.

HART, H.L.A. O Conceito de Direito. São Paulo: Martins Fontes, 2009.

KELSEN, Hans. Teoria Pura do Direito. 6. ed. Trad. João Batista Machado. São Paulo: Martins Fontes, 1999.

LAGES, Cíntia Garabini. A proposta de Ronald Dworkin em "O Império do Direito". Revista da Faculdade Mineira de Direito. Belo Horizonte: PUC Minas. v. 4. n. 7 e 8, jan./jun. 2001.

PEDRON, Flávio Quinaud e OMMATI, José Emílio Medauar. Teoria do Direito Contemporânea: Uma Análise das Teorias Jurídicas de Robert Alexy, Ronald Dworkin, Jürgen Habermas, Klaus Günther e Robert Brandom. Rio de Janeiro: Lumen Juris, 2019.

SOUZA CRUZ, Álvaro Ricardo de. Privilégio de foro e improbidade administrativa. In: SOUZA CRUZ, Álvaro Ricardo de (coord.). O Supremo Tribunal Federal Revisitado: o ano judiciário de 2002. Belo Horizonte: Mandamentos, 2003.

SOUZA CRUZ, Álvaro Ricardo de. Privilégio de foro e improbidade administrativa. In: SOUZA CRUZ, Álvaro Ricardo de (coord.). O Supremo 
Tribunal Federal Revisitado: o ano judiciário de 2002. Belo Horizonte: Mandamentos, 2003.

TORRANO, Bruno. Democracia e Respeito à Lei: Entre Positivismo Jurídico e Pós-Positivismo. Rio de Janeiro: Lumen Juris, 2015.

TORRANO, Bruno. Do Fato à Legalidade: Introdução à Teoria Analítica do Direito. Rio de Janeiro: Lumen Juris, 2014.

TORRANO, Bruno. OMMATI; José Emílio Medauar (coord.). O Positivismo Jurídico no Século XXI. Coleção Teoria Crítica do Direito. Volume 5. Rio de Janeiro: Lumen Juris, 2018.

Recebido em: 10-11-2020

Aprovado em: 25-11-2020

\section{José Emílio Medauar Ommati}

Doutorado em Direito Constitucional sobre liberdade de expressão e proibição da prática de racismo na Constituição de 1988 pela Universidade Federal de Minas Gerais em 2007. Mestrado em Direito Constitucional sobre o princípio da igualdade no Estado Democrático de Direito pela Universidade Federal de Minas Gerais em 2003. Graduação em Direito em 2000 pela Universidade Federal de Minas Gerais. Foi professor da Faculdade de Ciências Jurídicas de Diamantina, em Minas Gerais, até dezembro de 2008. Atualmente, é professor concursado adjunto IV da Pontifícia Universidade Católica de Minas Gerais - Campus Serro. Foi professor do Curso de Direito da Faculdade Santo Agostinho(Montes Claros), de agosto de 2015 a maio de 2016. Foi Coordenador do Curso de Direito da PUC Minas - Campus Serro de agosto de 2009 a janeiro de 2014. Retornou à Coordenação do Curso de Direito da PUC Minas Serro em fevereiro de 2017 exercendo seu mandato até janeiro de 2020. É professor do Programa de Mestrado e Doutorado em Direito da Universidade de Itaúna - MG, desde setembro de 2017. Dentre suas diversas obras jurídicas, destacam-se: Liberdade de Expressão e Discurso de Ódio na Constituição de 1988; Teoria da Constituição; Uma Teoria dos Direitos Fundamentais; todas publicadas pela Livraria e Editora Lumen Juris. Tem experiência na área de Direito, com ênfase em Direito Constitucional e Teoria do Direito, pesquisando sobre direito à diversidade. É casado e tem um filho.E-mail: emilioommati@gmail.com 


\section{Alexandre de Castro Coura}

Pós-doutorado como visiting scholar na American University Washington College of Law e visiting foreign judicial fellow no Centro Judiciário Federal em Washington D.C. Doutorado e mestrado em Direito Constitucional pela Universidade Federal de Minas Gerais (UFMG). Ocupou o cargo efetivo de professor adjunto nível II no Departamento de Direito da Universidade Federal do Espírito Santo (UFES). Atualmente é professor permanente do Programa de Pós-graduação Stricto Sensu - Mestrado e Doutorado - da Faculdade de Direito de Vitória (FDV), Coordenador do Grupo de Pesquisa Hermenêutica Jurídica e Jurisdição Constitucional (FDV/CNPq) e Promotor de Justiça (ES). Tem experiência nas áreas de Teoria do Direito e Direito Público, com ênfase em Direito Constitucional. Desenvolve e orienta pesquisas relacionadas a direitos e garantias fundamentais, hermenêutica jurídica, jurisdição constitucional e democracia. E-mail: acastrocoura@gmail.com

Pontifícia Universidade Católica de Minas Gerais, Campus Serro.

Praça João Pessoa, 74 Centro

39150000 - Serro, MG - Brasil 